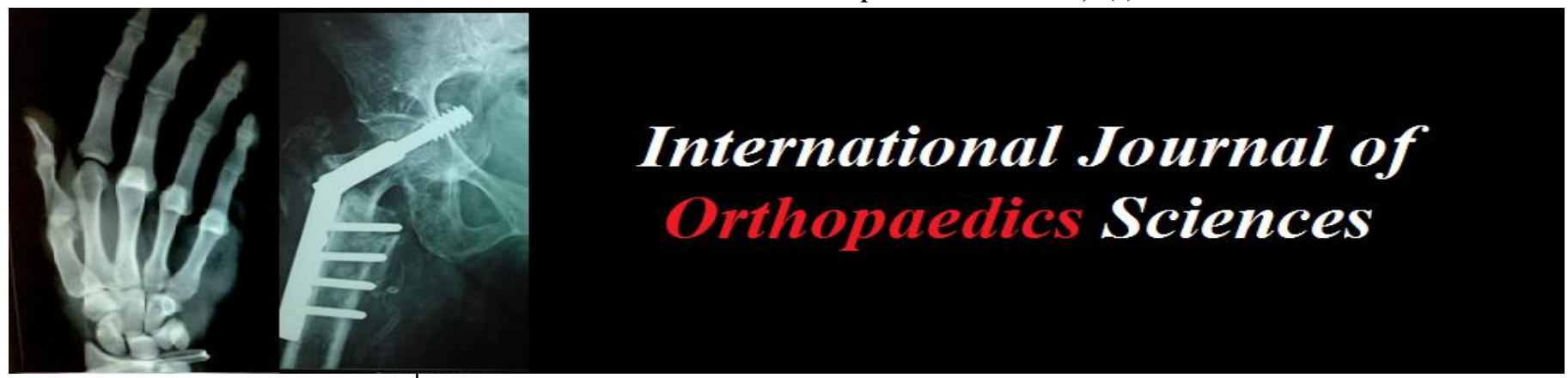

ISSN: 2395-1958

IJOS 2016; 2(4): 140-142

(C) 2016 IJOS

www.orthopaper.com

Received: 22-08-2016

Accepted: 23-09-2016

Dr. Vijayakumar AV

Assistant Professor, A J Shetty

Medical College, Mangalore,

Karnataka, India

Dr. Pramod G

Consultant, Orthopedician, Chikkaballapura, Karnataka, India

Correspondence

Dr Vijayakumar AV

Assistant Professor, A J Shetty

Medical College, Mangalore,

Karnataka, India

\section{Clinical profile of intercondylar fracture of distal humerus in adults}

\section{Dr. Vijayakumar AV and Dr. Pramod G}

DOI: http://dx.doi.org/10.22271/ortho.2016.v2.i4c.22

\section{Abstract}

There are two types of injury. One is "flexion type" where condyles are present anterior to the humeral shaft. In the "extension type" Ulna is directed anterior against the posterior aspect of trochleas separating the condyles and at the same time supra condylar position is fractured. On arrival of patients at casualty or at OPD level, the various points were noted down according to the proforma. On admission of the patient, a careful history was elicited from the patient and/or attendants to reveal the mechanism of injury and the severity of trauma. The patients were then assessed clinically to evaluate their general condition and the local injury. In the present series there were no cases of type I fractures. There were $5(25 \%)$ cases of type II fractures, $12(60 \%)$ cases of type III fractures and $3(15 \%)$ cases of type IV fractures. The mode of injury was direct fall on elbow or RTA.

Keywords: Humerus, intercondylar fracture, RTA

\section{Introduction}

The elbow is the last major joint in the vigorous kinetic chain that propels the ball during a throw. As a result of external torques and intrinsic function, the elbow structures are subject to three major stress experiences that can result in injury. Arm acceleration induces a valgus torque that imparts strain of the medial collateral ligament and potential compression at the radio humeral joint. Medial ligament failure and impact osteoarthritis are common pathologies. The medial epicondylar flexor pronator mass also is subjected to strain that may result in muscle tears. Deceleration demands challenge the elbow flexor mass, which may lead to tendinitis and contracture. Extra-articular fractures that traverse both columns of the distal humerus are most often the result of a fall. These fractures occur more commonly in children ${ }^{[1]}$.

Intra-articular fractures are probably caused by the impact of the proximal ulna against the trochlea, forcing apart the condyles of the distal humerus. These fractures are associated with high-energy trauma, such as falls and motor vehicle accidents. Varus and valgus movements, bone quality, and the energy of the injury influence the degree of comminution.

Condylar fractures of the distal humerus can occur with adduction or abduction forces of the extended forearm, which concentrates these forces to one side of the distal humerus. This creates compressive forces on the articular surface. An eccentric force applied to the posterior aspect of a flexed elbow can also produce a fracture of one condyle.

A fracture of the capitellum usually results from shear forces. This fracture commonly results from a fall onto an outstretched hand. Isolated fractures of an epicondyle are more common in children than adults. In the adult, this fracture is commonly caused by a direct blow to the epicondyle ${ }^{[2]}$.

There are two types of injury. One is "flexion type" where condyles are present anterior to the humeral shaft. In the "extension type" Ulna is directed anterior against the posterior aspect of trochleas separating the condyles and at the same time supra condylar position is fractured ${ }^{[3]}$.

Another mechanism was described by Wilson \& Cochrane, it occurs due to the splitting effect of humeral shaft as it is forced distally. In the extension type the humeral condyles lie behind the shaft. What ever the mechanism of injury there is always associated soft tissue injury, and some open laceration extend into fracture site. There is usually loss of bony continuity, since the fragments are displaced by opposed muscle traction, as it pulls the epicondyles distally and rotates the condyles, so that articular surface face a more proximal direction. 
This converts the trochlear sulcus into a narrow inverted "v" and hence not congruous with the ulnar articular surface. The action of biceps anteriorly and triceps posteriorly pull articular surface of Ulna proximally. In an opposing fashion, the humeral shaft is forced distally between the rotated condyles [4].

\section{Methodology}

\section{Inclusion criteria}

- Patients with closed intercondylar fracture of the distal end of the humerus

- $\quad$ Patients above the age of 18 years

- Patients medically fit for surgery

\section{Exclusion criteria}

- Compound fractures of the distal humerus

- Old fractures of the distal humerus

- Patients with extra articular distal humeral fracture

- Patients with distal neurovascular injury.

On arrival of patients at casualty or at OPD level, the various points were noted down according to the proforma. On admission of the patient, a careful history was elicited from the patient and/or attendants to reveal the mechanism of injury and the severity of trauma. The patients were then assessed clinically to evaluate their general condition and the local injury.

The general condition of the patient, the vital signs were recorded. Methodical examination was done to rule out fractures at other sites. Local examination of injured elbow revealed swelling, deformity and loss of function. Any nerve injury was looked for and noted.

\section{Results}

Table 1: Age Distribution

\begin{tabular}{|c|c|c|}
\hline Age in years & No. of & Percentage \\
\hline & cases & \\
\hline $21-30$ & 6 & 30 \\
\hline $31-40$ & 5 & 25 \\
\hline $41-50$ & 2 & 10 \\
\hline $51-60$ & 7 & 35 \\
\hline Total & 20 & 100 \\
\hline
\end{tabular}

In this series, $6(30 \%)$ patients were between $21-30$ years, 5 (25\%) patients were between 31-40 years, 2 (10\%) patients were between 41-50 years and patients between 51-60 years were $7(35 \%)$. The range of age was between $21-58$ years, with mean age of 43.4 years. The maximum incidence was between 51 to 60 years i.e. 7 cases $(35 \%)$.

Table 2: Gender distribution

\begin{tabular}{|c|c|c|c|}
\hline Sex & & No. of & Percentage \\
\hline & & cases & \\
\hline Males & & 11 & 55 \\
\hline Females & & 9 & 45 \\
\hline Total & 20 & 100 \\
\hline
\end{tabular}

In the present series there were $11(55 \%)$ were males and $9(45 \%)$ were females with Male: female ratio of
Table 3: Side involved

\begin{tabular}{|c|c|c|}
\hline Side involved & No. of & Percentage \\
\hline & cases & \\
\hline Right & 9 & 45 \\
\hline Left & 11 & 55 \\
\hline Total & 20 & 100 \\
\hline
\end{tabular}

Right upper limb was involved in $9(45 \%)$ cases and left upper limb in $11(55 \%)$ cases.

Table 4: Mode of injury

\begin{tabular}{|c|c|c|}
\hline Mode of injury & No. of & Percentage \\
\hline & cases & \\
\hline Direct fall & 10 & 50 \\
\hline Road traffic accident & 10 & 50 \\
\hline Total & 20 & 100 \\
\hline
\end{tabular}

In this series 10 cases (50\%) were due to direct fall injury and 10 cases $(50 \%)$ were due to road traffic accident.

Table 5: Type Of Fracture: (Riseborough Radin classification)

\begin{tabular}{|c|c|c|}
\hline Type of fractures & No. of & Percentage \\
\hline & cases & \\
\hline I & - & - \\
\hline II & 5 & 25 \\
\hline III & 12 & 60 \\
\hline IV & 3 & 15 \\
\hline
\end{tabular}

In the present series there were no cases of type I fractures. There were $5(25 \%)$ cases of type II fractures, 12 (60\%) cases of type III fractures and $3(15 \%)$ cases of type IV fractures.

\section{Discussion}

In our study fractures were commoner in the fifth and sixth decade with average age being 43.4 years (21-65). Our findings are comparable to the study made by Jesse B. Jupiter 1985, Gabel et al 1987, M. Bradford Henley et al 1987, KunChuang Want et al., In 1985 Jesse B. Jupiter et al found 57 years as the average age in their series. In 1987 Gabel et al found 45 years as the average in their series. In $1987 \mathrm{M}$. Bradford Henley et al found 32 years as the average age in their series. In 1994 Kun-Chuang Want et al, found 47 years as the average age in their series.

Table 6: Comparison of age

\begin{tabular}{|c|c|c|}
\hline Series & Age in years & Range \\
\hline Jese B. Jupiter et al $1985^{[5]}$ & 57 & $17-79$ \\
\hline Gabel et al, $1987^{[6]}$ & 45 & $17-75$ \\
\hline M. Bradford Henley et al, $1987^{[7]}$ & 32 & $15-61$ \\
\hline Kun-Chuang Wang, et al, $1994^{[8]}$ & 47 & $20-68$ \\
\hline Present study & 43 & $21-65$ \\
\hline
\end{tabular}

Our series had a male predominance with $55 \%$ and $45 \%$ female patient which were comparable to Kun-Chuang Wang et al, (1994) study.

Jesse B. Jupiter et al, (1985) in his study noted about $47 \%$ male and $53 \%$ female, sex distribution. M. Bradford Henley et al in his study noted about $52 \%$ male and $48 \%$ female incidence. Kun-Chuang Wang et al, in his study noted $60 \%$ male and $40 \%$ female incidence. Male predominance is probable due to their increased involvement in outdoor activity level. 
Table 7: Comparison of gender

\begin{tabular}{|c|c|c|}
\hline Series & Male & Female \\
\hline Jesse B. Jupiter et al $1985^{[5]}$ & $16(47 \%)$ & $18(53 \%)$ \\
\hline M. Bradford Henley ${\text { et al, } 1987^{[7]}}^{[8]}$ & $17(52 \%)$ & $16(48 \%)$ \\
\hline Kun-Chuang Wang, ${\text { et al, } 1994^{[8]}}^{12(60 \%)}$ & $8(40 \%)$ \\
\hline Present study & $11(55 \%)$ & $9(45 \%)$ \\
\hline
\end{tabular}

In our series $50 \%$ of the cases were due to direct fall and $50 \%$ of cases had road traffic accident. Gabel et al accounted $100 \%$ of his cases to direct fall. M. Bradford Henley accounted $61 \%$ of his cases to road traffic accident, $39 \%$ due to direct fall. Kun-Chuang Wang, et al, accounted $30 \%$ of the cases to direct fall and $70 \%$ of the cases to road traffic accident. The results of the M. Bradford Henley et al, 1987 are comparable with our series.

Table 7: Comparison of mode of injury

\begin{tabular}{|c|c|c|}
\hline Series & RTA & Direct fall \\
\hline Gabel et al, $1987^{[6]}$ & - & $(100 \%)$ \\
\hline M. Bradford Henley et al, $1987^{[7]}$ & $20(61 \%)$ & $13(39 \%)$ \\
\hline Kun-Chuang Wang, et al, $1994^{[8]}$ & $14(70 \%)$ & $(30 \%)$ \\
\hline Present study & $10(50 \%)$ & $10(50 \%)$ \\
\hline
\end{tabular}

We accounted about $45 \%$ incidence of fractures in right side and $55 \%$ of the fracture in left side, which is also comparable to other studies.

Jesse B. Jupiter reported about $62 \%$ incidence of fractures in left distal end of humerus. M. Broadford Henley et al reported about $55 \%$ incidence of fractures in left distal end of humerus. Left sided predominance is probable due to direct fall injury, left sided predominance which is common in our series.

Table 8: Comparison of side involved

\begin{tabular}{|c|c|c|}
\hline Series & Right & Left \\
\hline Jesse B. Jupiter et al $1985^{[5]}$ & $13(38 \%)$ & $21(62 \%)$ \\
\hline M. Bradford Henley et al, $1987^{[7]}$ & $15(45 \%)$ & $18(55 \%)$ \\
\hline Present study & $9(45 \%)$ & $11(55 \%)$ \\
\hline
\end{tabular}

In our series we accounted no cases of fractures of RR type I, $25 \%$ fractures of RR type II, $60 \%$ fractures of RR type III and $15 \%$ fractures of RR type IV.

Gabel et al in his series noted about $23 \%$ of fractures of RR type I, $15 \%$ fractures of RR type II, $31 \%$ fractures of RR type III and $23 \%$ fractures of RR type IV. M. Bradford et al in his series noted about $9 \%$ of fractures of RR type I, $12 \%$ fractures of RR type II, $43 \%$ fractures of RR type III and 36\% fractures of RR type IV.

Table 9: Comparison of type of fracture

\begin{tabular}{|c|c|c|c|c|}
\hline & & \multicolumn{2}{|c|}{ R.R. types } & \\
\hline Series & I & II & III & IV \\
\hline Gabel et al, $1987^{[6]}$ & $3(23 \%)$ & $2(15 \%)$ & $5(39 \%)$ & $3(23 \%)$ \\
\hline M. Bradford Henley et al, $1987^{[7]}$ & $3(9 \%)$ & $4(12 \%)$ & $14(43 \%)$ & $12(36 \%)$ \\
\hline Present study & - & $5(25 \%)$ & $12(60 \%)$ & $3(15 \%)$ \\
\hline
\end{tabular}

\section{Conclusion}

- Inter condylar fractures of the distal humerus are commoner in fifth and sixth decade of life with male predominant in high incidence of fracture due to outdoor activity.

- Inter condylar fractures demands careful evaluation, classification of fracture type and pre-operative planning.

\section{References}

1. Jacquelin P, Philip AD. Biomechanics of the elbow. Chapter-15 in Operative techniques in upper extremity sports injuries, Mosby, 1996, 391-401.

2. Helfet DL, Hotchkiss RN. Internal fixation of the distal humerus: A biomechanical comparison of methods. J Orthop Trauma. 1990; 4:260-264.

3. Johnson $\mathrm{H}$, Olerud S. Operative treatment of inter condylar fractures of the humans. J Trauma. 1971; 11:836-843.

4. Lawrence X. Webb Fractures of the distal humerus. Chapter-23 In Rockwood and Green's fractures in adults. 5th Edn. Lippincott Williams and Wilkins, 954-971.

5. Jupiter JB, Neff U, Holzach P. Intercondylar fractures of the humerus: An operative approach. J Bone Joint Surg Am. 1985; 67:226-238.

6. Gerard TGl, Gregory H, James BB. Intraarticular fractures of the distal humerus in the adult. Clin Orthop \& Related Research. 1987; 216:99-108.

7. Henley BM. Intra-articular distal humeral fractures in adults. Orthop Clin North Am Jan, 1987; 18(1):11-23.

8. Kun CW, Hsin NS, Kuo-Yao H. Intercondylar fractures of the distal humerus: routine anterior subcutaneous transposition of the ulnar nerve in a posterior operative approach. J Trauma. 1994; 36(6):770-773. 